\title{
Latest Trends in Problem Solving Assessment
}

\author{
http://dx.doi.org/10.3991/ijes.v4i2.5800 \\ Maria Karyotaki, Athanasios Drigas \\ 1 N.C.S.R. 'Demokritos', Institute of Informatics and Telecommunications, Net Media Lab, Athens, Greece
}

\begin{abstract}
Problem solving is the skill that coordinates all the cognitive, metacognitive and behavioral processes taking place when individuals encounter a previously unprecedented situation or difficulty. Metacognitive processes seem to play the most important role for resolving a problematic situation as individuals reflect on their acquired knowledge, skills and experiences, thus become aware of their capabilities and how to regulate them. Therefore, metacognitive awareness is the competence that mostly assists individuals in their attempt to construct new knowledge and reach their goals. Furthermore, individuals' self-assessment and peerassessment processes could reveal their level of metacognitive awareness and therefore, by far, their problem solving competency. Consequently, ICTs could capture individuals' problem solving skills through tracking down and analyzing the latters' cognitive and metacognitive processes as well as their behavioral patterns. The aforementioned computerbased assessment could consist of a fuzzy expert system with domain knowledge from an automated task-based test with particular solution strategies in combination with log data for identifying and classifying one's level of problem solving ability according to specific criteria.
\end{abstract}

Index Terms - problem solving skills assessment, collaborative problem solving skills assessment, life success.

\section{Physical And Mental Training}

Ozen's experimental study introduced practical sport climbing training as a means for enhancing primary students' problem solving, communication, confidence and locus of control abilities. Senior cognitive skills, such as problem solving can be improved through students' active learning methods, which aim at participants' exploring and applying knowledge, themselves. Furthermore, problem solving skills are connected to individuals' positive self-efficacy perception and by that, to the latter's personal development and socialization. As a result, students stand a good chance of having social harmony and success in their life. The self-evaluation measurement tool regarding students' acquired problem solving skills after six weeks of artificial wall climbing activities was the Problem Solving Inventory for Children. This instrument was originally developed by Serin, Serin and Saygili in 2010 and it consists of 25 items scored 1-5 points as a Likerttype scale. Study results showed that the experimental group developed in terms of their self-confidence, selfcontrol and overall inner control mechanism manipulation, as they perceived themselves efficient to deal with any problem occurred by providing efficacious solutions. Therefore, problem solving is a beneficial ability in multiple ways and by implementing similar trainings in the school curriculum children shall become healthy, happy, assertive and social individuals.

Ghanbari-E-Hashem-Abadi et al. made a semiexperimental study regarding the effects of integrative group therapy on participants' problem solving skills. Current research is founded on a conceptual framework combining the common factors of several theories, which relate problem solving skills enhancement to group cognitive-behavioral psychotherapy. More specifically, previous studies have illustrated that emotional intelligence, self-confidence and social compatibility were positively correlated with students' problem solving skills. According to the researchers, problem solving treatment is a fivestep process, encompassing understanding one's self, defining the problem, making a list of different solutions, deciding about the most suitable solution and applying the selected solution. The assessment tool implemented was Cassidy and Long's questionnaire for problem solving skills, measuring six factors (insolvency, problem solving control, creativity, confidence in problem solving, avoidance, closeness). Overall, the mental treatment improved group members' social, mental and occupational function through the development of their problem solving skills (2).

Safari et al. measured the effects of metacognitive instruction on university students' problem solving skills. Metacognition in combination with problem solving skills are undoubtedly beneficial factors for enhancing students' learning and thus, promoting their academic performance. The Problem Solving Inventory (PSI) by Heppner (1988) was used to measure medical students' perceptions on their problem solving behaviors after $200 \mathrm{~h}$ of training sessions on metacognitive problem solving. Students' problem solving confidence, personal control on emotions and behaviors as well as coping styles were all improved on account of the metacognitive instruction program (3).

Bezanilla et al. designed a serious game for training and assessing university students' problem solving and entrepreneurship competences. These two competences are transversal and have been related to students' improved employability level. Thus, such a competence-based assessment model would orientate university teaching methodology towards integrating elements, such as knowledge, skills, procedures and attitudes. In this specific game there are multiple-type of interactive activities, ranging from mere solving cases and simulations to problem-based learning scenarios, which all have a clearly established level of competence and indicators. Notwithstanding the coherent and integral Competence Assessment Model followed by the researchers, the game necessitates additional assessment criteria originating from students' peer interaction and assessment, especially through the latter's collaboration (4).

Shute et al. examined the effects of the Portal 2 video game on children's problem solving skills. The researchers argued that the problem solving skills acquired in the game can be transferred beyond the immediate game environment. Thus, stealth in conjunction with external as- 
sessment methods were used in order to measure gamers' problem solving skills in the form of log files and intelligence tests, respectively. Nevertheless, the findings revealed that players' problem solving skills were not significantly improved either way. Therefore, future studies should adopt self-assessment in accordance with other quantitative measurement tools in order to investigate on the transferability of the gained problem solving skills to real life situations (5).

Harandi et al. made an experimental study on high school students' problem solving performance and social skills after training the formers' metacognitive strategies. This Metacognitive training course lasted for 6 weeks and encompassed hierarchically all the necessary strategies that would turn students into self-monitoring and selfregulated learners. The strategies involved in the training sessions were determining the goal, planning, supervising, evaluating and making mistake diagnosis. The Problem Solving Inventory measured students' perceived problem solving skills. The findings revealed that the treatment group outperformed significantly the control group in both problem solving performance and social skills. Moreover, future research should focus on developing psychological assessment instruments based on the internal relations between students' ability to apply metacognitive and problem solving strategies (6).

Bicer et al. explored the effect of writing as a constructive process associated with developing middle school students' mathematical problem solving skills. Researchers provided students with a six week supplemental instruction in the writing process and more specifically in interpreting information, writing mechanics, generating story problems and solving each other's generated problems. The problem solving tests measured students' ability to encounter complex cognitive problems, generate problems as well as correct their answers. It turned out that students' problem solving skills increased due to being trained in gathering, analyzing, interpreting and explaining their thoughts. Besides students' cognition, such as their reasoning skills and mathematical thinking skills, students' metacognitive processes were also supported. Through the realization of their own thinking about mathematics, teachers also realize students' mathematical misconceptions, level of understanding, beliefs and feelings (7).

\section{TEACHER EDUCATION}

Karabacak et al. investigated candidate teachers' problem solving skills as an essential component of their professional efficiency in relation to their gender, educational rank, department of studies, class and graduated high school. As far as educational studies are concerned, teachers need to be able to train their students' problem solving skills, especially concerning mentally disabled as well as pre-school children. Moreover, through exploring manageable and solvable problems, teachers may set the grounds for improving individuals' capacity to cope with any problem, however basic or complex, in life. Furthermore, there has been a growing interest in examining candidate teachers' demographical data in order to address, first and foremost, their own educational needs. Data collection was performed through the "Problem Solving Inventory" (PSI) self-perception measurement tool. This 35 -item scale follows reverse scaling, with minimum score corresponding to high problem solving skills. It evaluated candidate teachers' appraisal towards their problem solving capacities and it consists of three factors; individual's problem-solving confidence (PSC), individual's approach-avoidance style (AAS) and one's personal control (PC). Findings of the study revealed that candidate teachers' perceived problem solving skill level is low. In addition, no meaningful relation between candidate teachers' personal profile and their self-perceived problem solving skill acquisition was substantiated. As a result, through structuring a fruitful educational environment for teachers in terms of their training and assessment practices may bring about significant changes in the educational system, as a whole (8).

Kuehl et al. made a comparative study on pre-service and in-service teachers' use of a rubric designed to assess $4^{\text {th }}$ grade students' mathematical problem solving. U. S. school teachers have shown a growing interest in measuring their students' process and progress of learning as well as providing the latter with effective feedback. By investigating pre-service and in-service teachers' attitudes and confidence in using rubrics both teacher education can be renewed and the instructional and assessment methodology at schools may be reexamined. Apart from the $4^{\text {th }}$ grade students' mathematics work samples, researchers developed and implemented a 5-point likert scale rubric tool for measuring students' mathematical problem solving. The assessment criteria encompassed Mathematical Knowledge of Multiplication, Division and Number Sense, understanding of the problem, accuracy, process and Mathematical Reasoning Skills. Eventually, teachers' experience was a considerable factor for their expressing greater confidence and positive attitudes towards rubric assessment. Moreover, in-service teachers made a rather thorough analysis on their students' potential improvement. Notwithstanding, pre-service teachers differed less in their rubric scores. It seems that in-service teachers' varied experience has an effect on both their assessment ratings and their attitudes. Therefore, teacher education programs should promote the development and implementation of such rubrics for establishing a common ground for students' effective assessment in classrooms (9).

Uzunoglu et al. made a research on the relation between pre-school teachers' problem solving approaches and their epistemological beliefs, perceptions of creativity levels and thinking styles. According to the researchers, problem solving permeates various aspects of individuals' lives including their needs, goals, values, habits, attitudes as well as their cognitive, affective and behavioral skills. In this sense, the Problem Solving Inventory by Heppner and Petersen (1982) was used as the measurement tool for preschool teachers' problem solving approaches. Ultimately, the relation delineated above was confirmed and especially creativity level perceptions were the most important predictor of teachers' perceived problem solving skills. Moreover, teachers that believed learning depends on studying, think innovatively and perceive themselves as having effective creative skills tend to acquire higher levels of problem solving skills. Therefore, teachers, let alone pre-school teachers, who train their creativity, problem solving and innovative thinking style, shall make a difference in the entire quality of education (10).

Kaya et al. explored elementary candidate teachers' perceptions of their problem solving skills in relevance to the formers' personal profile. The Problem Solving Inventory (PSI) by Heppner and Petersen investigated teachers' 
perceptions of their problem solving skills and strategies in conjunction with collecting participants' personal information, such as class, gender, region and settlement before studying, level of family income and leisure activities. Candidate teachers' problem solving skills were not found to be related to the participants' personal profile. Notwithstanding, candidate teachers were rather impulsive and had a tendency to perform less monitoring processes. Therefore, problem solving education should be placed in the center of teacher education as a means for elevating teachers' problem solving, social as well as metacognitive skills (11).

\section{STANDARD EDUCATION}

Ahmadi investigated the relation between Selfregulated learning strategies with Stress Collation and Problem Solving strategies. Self-regulated learning as well as the methods of struggling with stress and problem solving seems to be interlinked and all connect to students' self-confidence and self-efficiency towards learning, thus, their academic success. The research instruments employed were three questionnaires, one of which measured students' self-perceived problem solving skills by Heppner (1988). The results of the study verified that selfregulated learning is as a multi-objective procedure that was found relative both to the process of Stress Collation and Problem Solving. Therefore, training students the way to make reports on the exact steps as to how they can tackle with a problem in order to reach a proper solution resembles the self-regulated learning methodology implemented at schools. Finally, all methods presented above have indisputably multiple benefits and lead to students' overall competence and flexibility (12).

Veloo et al. made a survey on the association between college students' gender and their metacognitive awareness reading strategies. In the present study, three factors pertinent to students' reading strategies are examined in relation to their gender. These are the Global Reading Strategies, the Problem-Solving Strategies and the Support Reading Strategies. The Global Reading Strategies entail previewing and skimming the text as well as adjusting one's expectations during reading. The Problem-Solving Strategies include reading with adjusting speed according to text difficulty, pausing to reflect, rereading the text, visualizing the text, reading aloud and guessing the meaning of unknown words. The Support Reading Strategies refer to the practical strategies applied by the reader such as using dictionaries or taking notes while reading. The aforementioned factors are measured in the Metacognitive Awareness Reading Strategies (MARSI), self-report questionnaire made by Mokhtari and Reichard in 2002. The MARSI questionnaire has already been used in previous studies in relevance to readers' gender, only with controversial findings. In this case, there has been found that gender is associated to students' reading strategies and more specifically, the Support Reading Strategies were significantly related to female students. Overall, more female students implemented Metacognitive Awareness Reading Strategies and both male and female students prefer to use the Problem Solving Strategies. Consequently, students' academic achievement is susceptible to teachers' being trained to use effective reading strategies in their classroom instruction, thus evoking a more holistic approach in the application of the strategies (13).
Ozyurt made a descriptive study on computer engineering students' critical thinking dispositions and problem solving skills as well as the relationship between them. Apart from other individuals, engineers need to be equipped with critical thinking and problem solving skills in order to deal with multiple and ambiguous problems. On the whole, making a survey on future engineers' critical dispositions and problem solving skills may raise the priority of these skills in the entire engineering education. The Problem Solving Inventory (PSI) by Heppner and Petersen (1982) was used to measure computer engineering students' perceived problem solving skills. This data collection tool was adapted to Turkish by Sahin, Sahin and Heppner in 1993 and includes 35 items on a 6-point Likert scale. The higher the total score achieved in the scale the less competent is the individual in problem solving. Generally, students were found to have a high level of both their critical dispositions and problem solving skills, whereas only a poor relationship was found between the two skills. Additionally, no relationship was found concerning the aforementioned skills to either students' gender or grade (14).

Greiff et al. made a cross-lagged longitudinal study on the relation between students' complex problem solving skills and their working memory and fluid reasoning thinking processes. More specifically, the study aimed to discover how complex problem solving skills emerge and manifest themselves. Complex Problem solving Skills (CPS) have already been tied to students' academic and occupational achievement as well as to their life success. The CPS construct (knowledge acquisition \& knowledge application) was measured through MicroDyn tasks, varying in difficulty and with maximum duration of $1 \mathrm{~h}$. The results of the study confirmed that working memory and fluid reasoning are precursors of complex problem solving skills as students transcend from childhood to adolescence. Furthermore, the aforementioned finding verified of the critical role of education in mastering students' CPS proficiency and development (15).

Greiff et al. explained that the cognitive experimental problem solving research has shed light on the cognitive abilities and components of the problem solving process in combination to improving the measurement characteristics of problem solving tasks. The Programme for International Student Assessment (PISA) has adopted the problem solving construct as one of the core-elements in the educational assessment of 15-year-old high school students across all member states of the Organization for Economic Cooperation and Development (OECD). Until now the above large-scale assessment has measured students' Analytical Problem Solving (APS), Interactive Problem Solving (IPS) as well as Collaborative Problem Solving (ColPS). Those different types of problem solving assessment depict the different conceptions of problem solving, although the basic mental processes involved were knowledge acquisition and knowledge application. Future research on the theoretical understanding and the empirical side of problem solving should entail an automated test with particular solution strategies and the use of log data from machine learning methods, network analysis algorithms or cognitive and educational data mining. The rich process data generated by large- scale, computerbased assessments of problem solving skills should be analyzed either through the structural equation modeling 
or the item response theory in order to capture participants' cognitive processes and behavioral patterns (16).

Altuns et al. investigated the interrelation between 1112 year old children's playing regular educational games and their problem solving skills. Problem solving constitutes a way of effectively learning and developing individual skills and it is the most important process in education. For that reason, the researchers introduced educational games as a learning activity for promoting children's problem solving skills. Thereby, the Problem Solving Inventory for Children was used to capture their perceptions on their acquired problem solving skills. The findings showed significant changes on students' confidence and self-regulation processes (17).

Murni et al. introduced a metacognitive-based learning method in an attempt to develop junior high school students' mathematical problem solving abilities. This method was aiming at raising students' self-awareness as to how to design, monitor and evaluate their problem solving strategies. Moreover, students had the opportunity to enhance their self-confidence, self-respect, independency, responsibility and cooperativeness, thus they learned how to adjust to the environment, tackling with everyday problems. The Mathematical Problem Solving Ability test was administered to students in order to measure their ability in understanding a problem, devising a plan, carrying out the plan and finally, evaluating the problem solving result. The results confirmed the hypothesis that students' mathematical problem solving ability is significantly related to the development of their metacognitive behavior. In conclusion, metacognitive strategies are teachable and boost students' problem solving skills as well as their overall attitude towards learning (18).

Kobayashi et al. developed and validated a multidimensional scale of life skills in late childhood. This psychological measurement tool was structured on the basis of assessing comprehensive life skills in combination with psychological and emotional factors for capturing students' inner motivation in daily-life situations. The present scale stems from the concept of "zest for living", that is the promotion of qualities and abilities necessary for academic achievement and self-actualization, such as selflearning abilities, problem solving skills and skills for relating with others. Children ranging from 6 to 12 years old were tested on their problem solving/synthesis, relationship with friends, personal manners, decision making and future planning, self-learning, collecting and using information as well as their leadership. Furthermore, measuring school children's life skills could advocate their future careers and upgrade their everyday living conditions (19).

Ozsoy et al. investigated third grade students' reading comprehension skills in relation to their mathematical problem solving skills. The synergy of students' problem solving and reading comprehension skills lead to the accomplishment of elementary school children's goals. Therefore, examining students' possible transfer of acquired strategies and behaviors in new situations with problems that include the comprehension of a text would verify of the interrelation between the aforementioned skills. Notwithstanding, while evaluating problem solving and reading comprehension skills, individual differences, such as personal eagerness or interests should be taken into consideration. The instrument applied in order to determine students' problem solving skills was the prob- lem solving think-aloud protocol following Polya's problem solving stages. The findings of the study concluded in students' need for the concurrent development of their problem solving, reading comprehension as well as thinking skills, in general (20).

\section{Professional DeVElopment}

Mankad et al. introduced a fuzzy expert system that predicts candidate employees and standard employees' level of ability according to the Theory of Multiple Intelligences. Employees' ability to work with real life problems is identified and classified through adopting five basic types of intelligence from the theory of Multiple Intelligences. The types of Intelligence included were logical, verbal, interpersonal, intrapersonal and moral. The proposed system architecture used domain knowledge either from interviews, multiple references or from example sets. The domain knowledge was modified by a human expert. Different sets of interactive, multiple choice questionnaires correspond to different user categories; higher secondary education students, college students and professionals. These total score is shown to the users and the system decides on their selection or qualification status. Moreover, the system can make suggestions and present different tutorials so as to enhance the types of intelligence lacking for each user, respectively (21).

Hamalainen et al. made an in-depth study on the adults' with a VET background, problem solving skills in technology-rich environments (TREs). The present study unravels the eminent role of the European workforce's problem solving skills as far as their occupation and whole of the European welfare and competitiveness are concerned. Therefore, training adults' problem solving skills becomes an issue of top priority in, at least, all European educational systems. More specifically, the study investigated on European adults' level and distribution of problem-solving skills in technology-rich environments in relation to their educational background. Data coming from the Programme for the International Assessment of Adult Competencies (PIAAC) led by the Organization for Economic Co-operation and Development (OECD) and the Eurostat classification of the VET approaches were used for the study. The problem solving survey focused on the abilities to solve problems for personal, work and civic purposes by setting up appropriate goals and plans as well as by accessing and making use of information through computers and computer networks. The results clearly show that VET adults lack of or have low problem solving skills in Europe. In advance, adults with VET background performed lower than adults with other educational backgrounds. Therefore, future research should thoroughly examine on the educational aspects of successful problem solving processes in technology-rich environments, as a whole (22).

Ahmad et al. initiated an ICTC (Information Communication Technology Competency)-Test measuring postgraduate students' critical thinking skill, problem solving skill, information technology and communication skill as well as communication and management skill. The aim of the aforementioned instrument was either to assist graduates in identifying the career that is more suitable to them or to assist employers in accruing efficient employees through measuring the latters' abilities. More specifically, current assessment tool measures students' ability to define their main goal in an assignment as well as to access, 
PAPER

evaluate, manage and integrate information. Finally, students had to construct and communicate new knowledge using ICT applications. This task-based assessment with the form of problem-solving scenarios necessitates the presence of a clear scoring rubric while producing a written answer, preparing a verbal answer or creating a specific product. Thus, efficient problem solvers arising from the test signify students' capacity to cope with problems in everyday life and simultaneously in their future working fields (23).

\section{PROBLEM-BASED LEARNING}

Morales Bueno assessed first year engineering students' problem solving skills as a result of a hybrid problembased learning approach for a General Chemistry course. The three tests developed by the researcher addressed the third out of the three cognitive components (cognitive functions, beliefs and knowledge structure) assessed in problem solving according to Sugrue; knowledge structure is a three level component in terms of its connectivity, integration and consistency. At the first level, students had to identify examples of a concept, while at the second level students had to select the best explanation of a particular event. Finally, at the third level students had to select the correct procedure either to identify concepts in a given situation or to change a concept status through manipulating the concepts involved. The three tests were validated by five judges in combination with performing a pilot study for their internal consistency and coherence. Overall, the results showed that the three tests provided questions corresponding to varying level of students' knowledge structure. Thus, the tests offered internal discrimination. Conclusively, students attending problembased learning courses may be assessed on the grounds of Sugrue's model for assessing problem solving skills, especially in relation to their knowledge structure (24).

Tadeu et al. made a study on the structural validity and reliability of the Problem Solving Scale PortuguesePSSPT, a 25 item scale, divided into three factors (Attention, Problem Solving and Memorization). The purpose of the inventory was to measure preschool children's problem solving skills, after the latter's board game experience. According to PISA 2015, problem solving skills embrace a compound of mental processes, such as explore and understand, represent and formulate, plan and execute as well as monitor and reflect. The measurement tool, adopted from Willoughby-Herb and Neisworth (1983) was found effective both as far as its validity and its reliability, is concerned. The current scale may be used for measuring kindergarten children's problem solving skills in future experimental studies (25).

Kaya et al. investigated the validity and reliability of the Turkish version of the Problem Solving Scale, which was developed by Willoughby-Herb and Neisworth in 1983. The 5-point Likert type scale consisted of 25 items and measured Turkish preschool students' problem solving skills. Problem solving is considered to be a concrete procedure, which is characterized by consecutive and systematic phases. At first, students become aware of the problem, they define it and try to find possible solutions and finally, they implement the existing solutions until the problem is eliminated. According to the confirmatory factor analysis (CFA) as well as to the internal consistency and the item analysis of the scale, the scale was found valid and reliable for its use in preschool children. Addi- tionally, three alternative factors emerged as measurement properties of the scale; Attention, Memory and Reproduction and Problem Solving (26).

Sevim examined elementary school $7^{\text {th }}$ grade students' academic achievement and problem solving skills deriving from the adoption of the subject jigsaw technique, a cooperative learning method. Cooperative learning experiences develop students' problem solving skills and such effective learning practices enhance their academic achievement as a whole. In turn, problem solving skills in cooperative learning environments encompass both cognitive and social skills for the plan formation, the intermediate plan revision and finally the implementation and evaluation of it. First of all, students' problem solving skills lay on their ability to trace and use their own and their fellow group members' efficacies. Secondly, they must establish a common ground for exchanging experiences and finally, they must perform self-monitoring processes as well as controlling processes while applying and evaluating their group plan. Therefore, the researcher chose the subject jigsaw technique, which incorporates both individualized and cooperative learning techniques in order to study their effects on students' problem solving skills and academic achievement. The Problem Solving Inventory for Children (PSIC), self-perception measurement tool, by Serin, Bulut Serin and Saygili (2010) and the Narration Types Achievement Test (NTAT) were deployed as research instruments. The results showed that the experimental group's academic achievement and problem solving skills had grown after implementing the aforementioned technique (27).

Temel measured pre-service teachers' critical thinking dispositions and perceptions of problem solving ability after implementing a problem-based learning method in a chemistry course. Both critical thinking dispositions and perceptions of problem solving ability are integral parts of one's critical thinking capability and problem solving capacity, respectively. Therefore, the researcher investigated the aforementioned constructs in an attempt to relate them to the Problem Based Learning teaching approach. The Problem Solving Inventory (PSI) by Heppner and Petersen (1982) and the California Critical Thinking Disposition Inventory (CCTDI) were the research tools. Findings of the study showed that the PBL approach was significantly related only to student teachers' perceptions of their problem solving ability, probably because critical thinking requires more time to develop (28).

\section{RESEARCH HighLIGHTS}

Problem solving constitutes a moderator skill for coordinating many cognitive, metacognitive and behavioral competences needed in both every day and complex problem solving cases. Such competences are working memory, fluid reasoning, mathematical thinking, reading comprehension, creativity, metacognitive awareness, inner-control, entrepreneurship, time management. Education is interrelated to problem solving as the former assists students' problem solving development and the latter is the mediator of the upgrade of the whole educational system. Moreover, individuals' self-perceptions on their problem solving skills constitute a major part of the current research methodology applied in problem solving assessment. Furthermore, future studies should focus on the bottom-up criteria rising from individuals' interaction with a problematic situation, including self-assessment 
criteria and peer-assessment criteria from collaborative tasks. ICTs could capture individuals' problem solving skills through providing immersive problem-based tasks and fuzzy expert systems with domain knowledge from the formers' cognitive, metacognitive and behavioral processes.

\section{CONCLUSIONS}

Problem solving is a top-level ability that orchestrates a whole set of cognitive, metacognitive and behavioral processes in every day problem solving situations. Research in problem solving assessment endorses its significance in the construct of intelligence and its mediating role in the progress of the educational systems worldwide. Therefore, through establishing a rigid problem solving construct researchers delineate the methodology for its effective development.

\section{REFERENCES}

[1] Ozen, G. : "Examining the effect of artificial wall climbing as a leisure time activity on children's problem-solving skills", Pegem Egitim ve Ogretim Dergisi, vol. 5(2), pp. 221-236, (2015).

[2] Ghanbari-Hashemabadi, B. Maddah-Shoorcheh, R. and MaddahShoorcheh, E. : "The effectiveness of Integrative Group Therapy on improving Problem-Solving Skills", Zahedan Journal of Research in Medical Sciences, vol. 16(5), pp. 1-5, (2014).

[3] Safari, $Y$ and Meskini, H. : "The effect of metacognitive instruction on problem solving skills in Iranian students of Health Sciences", Global Journal of Health Science, vol. 8(1), pp. 150-156, (2016). http://dx.doi.org/10.5539/gjhs.v8n1p150

[4] Bezanilla, M. J. Arranz, S. Rayon, A. Rubio, I. Menchaca, I. Guenaga, M. and Aguilar, E. : "A proposal for generic competence assessment in a serious game", New Approaches in Educational Research, vol. 3(1), pp. 42-51, (2014). http://dx.doi.org/10.7821/naer.3.1.42-51

[5] Shute, V. J. and Wang, L. : "Measuring problem solving skills in Portal 2", in P. Isaias et al. (eds.), E-learning Systems, Environments and Approaches, pp. 11-25, (2015). http://dx.doi.org/10.1007/978-3-319-05825-2_2

[6] Harandi, V. Eslami, S. H. Ahmadi, D. M. Darehkordi, A. : "The effect of metacognitive strategy training on social skills and problem - solving performance", Psychology \& Psychotherapy, vol. 3(4), pp. 1-4, (2013).

[7] Bicer, A. Capraro, R. M. and Capraro, M. M. : "Integrating writing into Mathematics classroom to increase students' problem solving skills", International Online Journal of Educational Sciences', vol. 5(2), pp. 361-369, (2013).

[8] Karabacak, K. Nalbant, D. and Topcuoglu, P. : "Examination of teacher candidates' problem solving skills according to several variables", Procedia-Social and Behavioral Sciences, vol. 174, pp. 3063-3071, (2015). http://dx.doi.org/10.1016/j.sbspro.2015.01. 1099

[9] Kuehl, G. Sofronas, K. Lau, A. : "Pre-service and In-service Teachers' Rubric Assessments of Mathematical Problem Solving", (2015), NERA Conference Proceedings 2014, Paper 1.

[10] Uzunoglu, H. and Demir K. : "Investigating the relationship between pre-school teachers' problem solving skills and their epistemological beliefs, creativity levels and thinking styles", Journal of Teacher Education and Educators, vol. 3(2), pp. 167-184, (2014).

[11] Kaya, D. Izgiol, D. and Kesan, C. : "The investigation of elementary mathematics teacher candidates' problem solving skills according to various variables", International Electronic Journal of Elementary Education, vol. 6(2), pp. 295-314, (2014).

[12] Altuns, M. and Hazar, M. : "Investigation of problem-solving skills in children aged 11-12 playing regular educational games regularly", Anthropologist, vol. 20(3), pp. 689-693, (2015).

[13] Murni, A. Sabandar, J. Kusumah, Y. S. and Kartasamita, B. G. : "The enhancement of junior high school students' abilities in Mathematical problem solving using soft skill-based metacognitive learning”, IndoMS-JME, vol. 4(2), pp. 194-203, (2013).
[14] Kobayashi, M. Gushiken, T. Ganaha, Y. Sasazawa, Y. Iwata, S. Takemura, A. Fujita, T. Asikin, Y. and Takakura, M. : "Reliability and validity of the multidimensional scale of life skills in late childhood, Education Sciences, vol. 3, pp. 121-135, (2013). http://dx.doi.org/10.3390/educsci3020121

[15] Ozsoy, G. Kuruyer, H. G. Cakiroglu, A. : "Evaluation of students' mathematical problem solving skills in relation to their reading levels", International Electronic Journal of Elementary Education, vol. 8(1), pp. 113-132, (2015)

[16] Mankad, K. B. and Sajja, P. S.: "Design of Fuzzy Expert System for Selection of Candidates using the Theory of Multiple Intelligence", International Journal of Advanced Research in Computer Science, vol. 4 (2), pp. 178-183, (2013).

[17] Ahmadi A. : "Relation between methods of struggling with stress and the method of solving problem by self-regulated learning", Procedia-Social and Behavioral Sciences, vol. 171, pp. 1273-1279, (2015). http://dx.doi.org/10.1016/j.sbspro.2015.01.241

[18] Veloo, A. Rani, M. A. and Hariharan, K. : "The role of gender in the use of Metacognitive Awareness Reading Strategies among Biology students", Asian Social Science, vol. 11(1), pp. 67-73, (2015).

[19] Ozyurt, O. : "Examining the Critical Thinking Dispositions and the Problem Solving Skills of Computer Engineering Students", Eurasia Journal of Mathematics, Science \& Technology Education, vol. 11(2), pp. 353-361, (2015).

[20] Greiff, S. Wustenberg, S. Goetz, T. Vainikainen, M.-P. Hautamaki, J. and Bornstein, M. H. : "A longitudinal study of higherorder thinking skills: working memory and fluid reasoning in childhood enhance complex problem solving in adolescence", Frontiers in Psychology, vol. 6, article 1060, pp. 1-9, (2015).

[21] Greiff, S. Holt, D. V. and Funke, J. : "Perspectives on Problem Solving in Educational Assessment: Analytical, Interactive and Collaborative Problem Solving", The Journal of Problem Solving, vol. 5(2), pp. 71-91, (2013). http://dx.doi.org/10.7771/19326246.1153

[22] Hamalainen, R. Cincinnato, S. Malin, A. De Wever, B. : "VET workers' problem-solving skills in technology-rich environments: European approach, International Journal for Research in Vocational Education and Training (IJRVET), vol.1(1), pp. 57-80, (2014).

[23] Ahmad, M. Karim, A. A. Din, R. and Albakri, I. S. M. A. : "Assessing ICT competencies among postgraduate students based on the $21^{\text {ST }}$ century ICT competency model", Asian Social Science, vol. 9(16), pp. 32-39, (2013). http://dx.doi.org/10.5539/ass.v9n $16 \mathrm{p} 32$

[24] Morales Bueno, P. : "Assessment of achievement in problemsolving skills in a general chemistry course", Journal of Technology and Science Education, vol.4(4), pp. 260-269, (2014). http://dx.doi.org/10.3926/jotse.100

[25] Tadeu, P. Kaya, M. Arslan, S. and Demir, S. : "Problem Solving Scale (PSSPT): a study of validity and reliability of the Portuguese version", Procedia-Social and Behavioral Sciences, vol. 106, pp. 2119-2124, (2013). http://dx.doi.org/10.1016/j.sbspro.2013.12.241

[26] Kaya, M. Arslan, S. Tadeu, P. and Demir, S. : "Problem solving scale (PSS-TR): a study of validity and reliability of the Turkish version, Procedia-Social and Behavioral Sciences, vol. 106, pp. 2125-2130, (2013). http://dx.doi.org/10.1016/j.sbspro.2013.12.242

[27] Sevim, O. : "Influence of the Subject Jigsaw Technique on Elementary School Seventh Grade Students' Academic Achievement and on Their Problem Solving Skills", GJRA-Global Journal for Research Analysis, vol. 3(8), pp. 79-85, (2014). http://dx.doi.org/10.15373/22778160/August2014/25

[28] Temel, S. : "The effects of problem-based learning on pre-service teachers' critical thinking dispositions and perceptions of problemsolving ability", South African Journal of Education, vol. 34(1), pp. 1-20, (2014). http://dx.doi.org/10.15700/201412120936

\section{AUTHORS}

Athanasios Drigas is a Research Director at IIT N.C.S.R. Demokritos. He is the Coordinator of Telecoms Lab and founder of Net Media Lab since 1996. From 1990 to 1999 he was the Operational manager of the Greek Academic network. He has been the Coordinator of Sev- 
PAPER

LATEST TRENDS IN PROBLEM SOLVING ASSESSMENT

eral International Projects, in the fields of ICTs, and eservices (e-learning, e-psychology, e-government, e-inclusion, e-culture etc). He has published more than 270 articles, 7 books, 25 educational CD-ROMs and several patents. He has been a member of several International committees for the design and coordination of Network and ICT activities and of international conferences and journals. (e-mail: dr@iit.demokritos.gr).
M. Karyotaki is with N.C.S.R. 'Demokritos', Institute of Informatics and Telecommunications, Telecoms Lab Net Media Lab, Agia Paraskevi, 153 10, Athens, Greece (e-mail: karyotakimaria@gmail.com)

Submitted 27 April 2016. Published as rsubmitted by the authors 29 May 2016. 